Adam Gregerman

\title{
Building on the Ruins of the Temple
}

\author{
Apologetics and Polemics in Early Christianity and Rabbinic Judaism
}

[Auf den Ruinen des Tempels bauen. Apologetik und Polemik im frühen Christentum und im rabbinischen Judentum.]

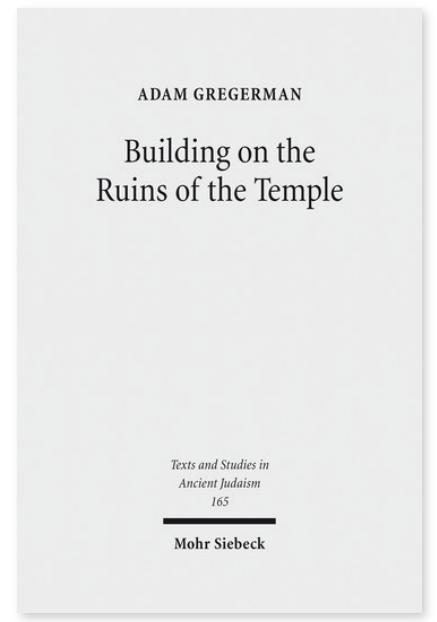

2016. XIV, 266 Seiten. TSAJ 165

ISBN 978-3-16-154521-4

DOI 10.1628/978-3-16-154521-4

eBook PDF 139,00€

ISBN 978-3-16-154322-7

Leinen $139,00 €$
Veröffentlicht auf Englisch.

In den Jahrhunderten unmittelbar nach der Zerstörung Jerusalems und des Tempels durch die Römer im Jahr 70 n.Chr. hatten Juden und Christen unterschiedliche Erklärungen für die vollkommene Zerstörung von Gottes Platz auf Erden. Adam Gregerman untersucht die Standpunkte, die er in drei frühchristlichen Texten (Justinus' Dialog mit dem Juden Tryphon, Origines' Contra Celsum und Eusebius' Beweis des Evangeliums) und einem rabbinischen Text (den Midrasch der Klagelieder) findet; alle Texte entstanden am selben Ort (Israel) und in etwa zur selben Zeit (den ersten Jahrhunderten nach 70). Der Autor prüft die Art und Weise, wie die Texte die Zerstörung deuten, um (im Fall der Christen) zu beweisen oder (im Fall der Juden) den Gegenbeweis unmöglich zu machen, dass ihre Gemeinde das Volk Gottes ist. Er veranschaulicht die apologetischen und polemischen Funktionen einzelner Erklärungen und zeigt, dass die Ansprüche der einen Gemeinde auf den Bund die der anderen Gemeinde ausschließen.

Adam Gregerman Born 1973; PhD in Religion at Columbia University; currently Assistant Professor of Theology and Religious Studies and Assistant Director, Institute for Jewish-Catholic Relations, Saint Joseph's University, Philadelphia, PA.

\section{Jetzt bestellen:}

https://mohrsiebeck.com/buch/building-on-the-ruins-of-the-temple-9783161545214?no_cache=1 order@mohrsiebeck.com

Telefon: $+49(0) 7071-923-17$

Telefax: +49 (0)7071-51104 